POLIBUTÁNICA

Núm. 40, pp. 1-27; México, 2015

DOI: $10.18387 /$ polibotanica.40.1

\title{
ESTUDIO FLORÍSTICO DE LA CUENCA BAJA DEL RÍO PAPAGAYO, GUERRERO, MÉXICO
}

\section{FLORISTIC STUDY IN THE LOWER PAPAGAYO RIVER BASIN, GUERRERO, MEXICO}

\begin{abstract}
Blanca Estela Carreto-Pérez ${ }^{1,2}$, Ángel Almazán-Juárez², Pablo Sierra-Morales ${ }^{3}$ y R. Carlos Almazán-Núñez ${ }^{3 *}$

${ }^{1}$ Maestría en Sistemas de Producción Agropecuaria, Universidad Autónoma de Guerrero, Unidad Tuxpan: Km 2.5 Carretera Iguala-Tuxpan, Iguala, Guerrero, 40030 México. ${ }^{2}$ Instituto de Investigación Científica Area Ciencias Naturales, Universidad Autónoma de Guerrero, Av. Lázaro Cárdenas s/n, Ciudad Universitaria, Chilpancingo, Guerrero. 39087. México.

${ }^{3}$ Unidad Académica de Ciencias Químico-Biológicas, Universidad Autónoma de Guerrero, Av. Lázaro Cárdenas s/n. Ciudad Universitaria, Chilpancingo, Guerrero. 39087, México. *Correo electrónico: oikos79@yahoo.com.mx
\end{abstract}

\section{RESUMEN}

Se presenta la composición florística de la cuenca baja del río Papagayo, Guerrero, México. El trabajo de campo se desarrolló de junio de 2011 a junio de 2012. Se identificaron un total de 204 especies de plantas vasculares, comprendidas en 73 familias y 163 géneros. Las familias Fabaceae, Poaceae, Asteraceae, Euphorbiaceae y Rubiaceae representaron el $41 \%$ del total de especies y el 38\% de los géneros en el área de estudio. Las formas biológicas predominantes en el área de estudio fueron las hierbas (81 especies), arbustos (67 especies) y árboles (49 especies). Se determinaron 10 tipos de vegetación, de los cuáles la selva baja caducifolia la que cubre la mayor superficie y presenta la mayor riqueza florística. Se registraron once especies bajo la categoría de amenazadas según la NOM-059-SEMAR-
NAT-2010, de las cuáles una es endémica a México (Rhizophora mangle).

Palabras clave: riqueza, flora, dicotiledóneas, vegetación, selva baja caducifolia, río Papagayo, planicie costera.

\section{ABSTRACT.}

We present the floristic composition of the Papagayo river basin, Guerrero, México. Field work was carried out from June 2011 to June 2012. We identified a total of 204 species of vascular plants, including 73 families and 163 genus. Families Fabaceae, Poaceae, Asteraceae, Euphorbiaceae and Rubiaceae represented $41 \%$ of all species and $38 \%$ of the genus in the study area. The herbaceous plant life form was the best represented with 81 species $(40 \%)$. Were determined 10 vegetation types, of which the 
tropical deciduous forest covers the largest area and has the richest flora. Eleven species were recorded under the category of threatened by NOM-059-SEMARNAT-2010, of which one is endemic to Mexico (Rhizophora mangle).

Key words: richness, flora, dicotyledonous, vegetation, tropical deciduous forest, Papagayo river, Coastal Plain.

\section{INTRODUCCIÓN}

A nivel nacional, el estado de Guerrero ocupa uno de los lugares más importantes por la gran variedad de plantas y animales que posee, producto de su compleja heterogeneidad espacial (Challenger, 1998). Un ejemplo de ello, es que de entre las 22000 y 30000 especies de plantas vasculares que se han registrado en el país, se estima que entre el 20 y $25 \%$ de esta flora se encuentra en Guerrero (Toledo, 1988; Rzedowski, 1991, Valencia-Ávalos et al., 2011). Además, para esta entidad se ha estimado que existen 4648 especies de Magnoliophyta, lo que representa el $26 \%$ de lo registrado en el territorio nacional (Villaseñor, 2003). Estas cifras ubican a Guerrero entre las cinco entidades de la república mexicana con mayor riqueza florística (Rzedowski, 1991; Mittermeier y Goettsch de Mittermeier, 1992; Toledo et al., 1997; Villaseñor, 2003). Algunas regiones en el estado son consideradas como centros de diversificación y endemismo de varios grupos de plantas como el género Bursera en el Cañón del Zopilote (Rzedowski et al., 2005; De-Nova et al., 2012) y los agaves en la región de la mixteca entre Guerrero y Oaxaca (Golubov et al., 2005). Sin embargo, la flora estatal no ha sido totalmente estudiada (Valencia-Ávalos et al., 2011), prueba de ello, es que en la actualidad se siguen describiendo nuevos taxones a nivel infra y supraespecífico (e. g., Jiménez y Martínez, 2000; Diego-Pérez y Calderón de Rzedowski, 2004).

Es indudable que el inventario florístico podría aumentar a medida que la exploración botánica se extienda a regiones poco exploradas, ya que la mayoría de los trabajos florísticos y de vegetación se han realizado en la porción central de la Cuenca del Balsas (Vargas y Pérez, 1996; Carreto y Almazán, 2004; Ávila et al., 2010; Almazán-Núñez et al., 2012; Reyes-García et al., 2012) y la Sierra Madre del Sur (Diego-Pérez et al., 2001; Catalán-Heverástico et al., 2004). Por el contrario, extensas áreas en los extremos oriente y poniente de la entidad aún no han sido lo suficientemente estudiadas, debido en gran medida por las vías de acceso y las condiciones de seguridad que dificultan el desarrollo de inventarios (Meza y López, 1997; Valencia-Ávalos et al., 2011).

La región de la planicie costera (PC) no es la excepción en cuanto a vacíos de conocimiento (Gallardo, 1996; Peralta-Gómez et $a l ., 2000)$. Esta región posee tipos de vegetación importantes para la conservación y de relevancia desde el punto de vista biológico, como los manglares, selvas medianas y extensos parches con diferentes niveles de sucesión de selva baja caducifolia (SBC). Con la finalidad de resumir e integrar el conocimiento de la flora de esta región, Peralta-Gómez et al. (2000) describieron la composición florística de la parte baja (0 a 300 m.s.n.m.) de la Costa Grande de Guerrero, indicando la presencia de 1047 especies. Estos mismos autores resaltaron que el reconocimiento de la flora de la región aun es preliminar. Una razón de ello son los esfuerzos dispersos que se han 
llevado a cabo por describir y aumentar el conocimiento de la composición florística (Oseguera y Mancilla, 1986; Fonseca y Lozada, 1993; Lozada, 1994; Gallardo, 1996; Diego-Pérez et al., 2000).

La cuenca baja del río Papagayo se encuentra principalmente dentro de esta región y su vegetación predominante es SBC. En esta zona, existe un fuerte proceso de deterioro de los ecosistemas nativos debido a la expansión de la frontera agropecuaria, la explotación desmedida de vegetación leñosa con fines de autoconsumo y el crecimiento demográfico (Gallardo, 1996; Peralta-Gómez et al., 2000). Estos aspectos se ven reflejados en la disminución de la riqueza florística y por ende en la calidad y la valoración del paisaje de la región (García-Romero et al., 2005). Este estudio tiene como objetivo principal contribuir con el listado de la flora existente en el área, donde además se incluyen algunos aspectos ecológicos, como riqueza por tipos de vegetación y forma biológica.

\section{ÁREA DE ESTUdio}

El área de estudio se localiza principalmente en la provincia biótica de la planicie costera del Pacífico y sólo una pequeña área en la Sierra Madre del Sur (fig. 1). Comprende parte de los municipios de Acapulco, Juan R. Escudero, San Marcos y Tecoanapa y cubre una superficie de $1228.7 \mathrm{~km}^{2}$, entre los paralelos $16^{\circ} 41^{\prime} 00^{\prime \prime}$ y $17^{\circ} 14^{\prime} 23^{\prime \prime}$ de latitud norte y $99^{\circ} 43^{\prime} 31^{\prime \prime}$ y $99^{\circ} 19^{\prime} 11^{\prime \prime}$ de longitud oeste (Almazán y Sorani, 2005).

Hidrológicamente se encuentra entre dos ríos, al norte con La Sabana y al sur con El Papagayo. Ambos pertenecen a la región hidrológica 20 (RH-20), Costa Chica de
Guerrero. El clima en general es cálido húmedo con lluvias mayores a $1000 \mathrm{~mm} /$ año. Las lluvias más intensas y con mayor frecuencia son aquellas que se presentan entre 40 y $80 \mathrm{~mm} / 24$ horas (Almazán y Sorani, 2005). Esta zona presenta una orografía accidentada, cuyo gradiente altitudinal abarca áreas desde el nivel del mar hasta más de $1500 \mathrm{~m}$ de altitud (fig. 1).

\section{MATERIAL Y MÉTODOS}

El trabajo de campo para la colecta botánica se llevó a cabo durante un año (de junio de 2011 a junio de 2012). En este tiempo, se realizaron recorridos con duración de cinco a siete días mensuales, trabajando en promedio nueve horas diarias. En la fase inicial del estudio se contó con apoyo de los mapas temáticos y topográficos de INEGI. Posteriormente, se generó el mapa de vegetación de la zona de estudio utilizando dos tipos de imágenes satelitales: sensores Lansat TM y QuickBird, con los que se determinaron los tipos de vegetación presentes y su estado de conservación, así como las vías de acceso y poblados cercanos. Este mapa se fue delineando con la ayuda de los muestreos en campo en los diferentes tipos de vegetación presentes en el área, al tiempo que se recolectaron por triplicado especies arbóreas, arbustivas y herbáceas que presentaron flor $\mathrm{y} / \mathrm{o}$ fruto.

El trabajo de colecta en cada uno de los tipos de vegetación de la zona fue mayor en aquellos ambientes con superficie territorial más extensa. Así, los puntos de colecta estuvieron mayormente concentrados en la $\mathrm{SBC}$, vegetación secundaria y bosques de pino y encino, y fueron menores en la selva mediana subcaducifolia, manglar y tular. Los ejemplares colectados fueron proce- 
sados y herborizados mediante técnicas convencionales siguiendo los criterios de Lot y Chiang (1986). Para algunas pocas especies su determinación se realizó de manera in situ con el uso de claves dicotómicas (e. g. Pennington y Sarukhán, 2005; Rzedowski et al., 2005) y por comparación con ejemplares del Herbario del Instituto de Investigación Científica Área de Ciencias Naturales de la Universidad Autónoma de Guerrero (IICACN-UAGro). Sin embargo, la gran mayoría fueron determinadas en el Laboratorio de Plantas Vasculares de la UNAM con el apoyo de especialistas por familia botánica y cuyas muestras botánicas (un par de ellas) fueron depositadas en este mismo laboratorio (números de colecta: 1 al 253). Un duplicado más se depositó en el Herbario del IICACN-UAGro.

El listado florístico se presenta de acuerdo con el sistema de clasificación de Cronquist (1981) e incluye el tipo de comunidad vegetal y su forma de crecimiento de acuerdo con Moreno (1984). En cada sección las familias están ordenadas alfabéticamente. La nomenclatura de los géneros y las especies, así como los nombres de los autores se verificaron en la base de datos de W3TROPICOS (www.mobot.org). Las categorías de riesgo que se utilizaron para revisar el estado de conservación de las especies presentes en el área de estudio, se basaron en la Norma Oficial Mexicana: NOM-059-SEMARNAT-2010 (SEMARNAT, 2010). La nomenclatura y la descripción de los tipos de vegetación y/o comunidades vegetales se basó en los criterios fisonómico-estructurales y de composición florística propuestos por Miranda y Hernández X (1963).

Debido a que la SBC fue el tipo de vegetación mejor muestreado por la mayor extensión territorial que abarca en el área de estudio, se estimó la riqueza total esperada con base en modelos no paramétricos basados en incidencia: estimador de cobertura basado en incidencia (ICE) y Chao2 (Chazdon et al., 1998). Los días de muestreo en este tipo de vegetación sirvieron como unidad de esfuerzo. Estos análisis se realizaron con ayuda del programa EstimateS v. 8.0 (Colwell, 2006).

\section{RESULTADOS}

\section{Florística}

Se registraron 204 especies correspondientes a 163 géneros y 73 familias (apéndice 1). El grupo mejor representado fue Magnoliopsida (apéndice 1). Las familias con mayor número de especies son Fabaceae con 43 especies (21.1\%), Poaceae 15 (7.4\%), Asteraceae 10 (4.9\%), Euphorbiaceae y Rubiaceae con ocho especies cada una (3.9\%; cuadro 1). El resto de las familias posee seis o menos especies (apéndice 1). La familia Fabaceae presentó también el mayor número de géneros (cuadro 1). Los estimadores de ICE y Chao2 indicaron que en la SBC de la cuenca del Papagayo se registró el 95\% del total esperado. Las formas biológicas predominantes en el área de estudio fueron las hierbas (81 especies), arbustos (66 especies) y árboles (50 especies; fig. 2). Del total de especies, diez se encuentran en la categoría de amenazadas no endémicas según la NOM-059-SEMARNAT 2010: Zinnia violacea (viuda), Tabebuia chrysantha, Tabebuia palmeri (roble), Calophyllum brasiliense (palo maría), Licania arborea (cacahuate), Sapium macrocarpum (chilamate), Peltogyne mexicana (palo morado), Mastichodendron capiri (capire), Laguncularia racemosa (mangle blanco), y 


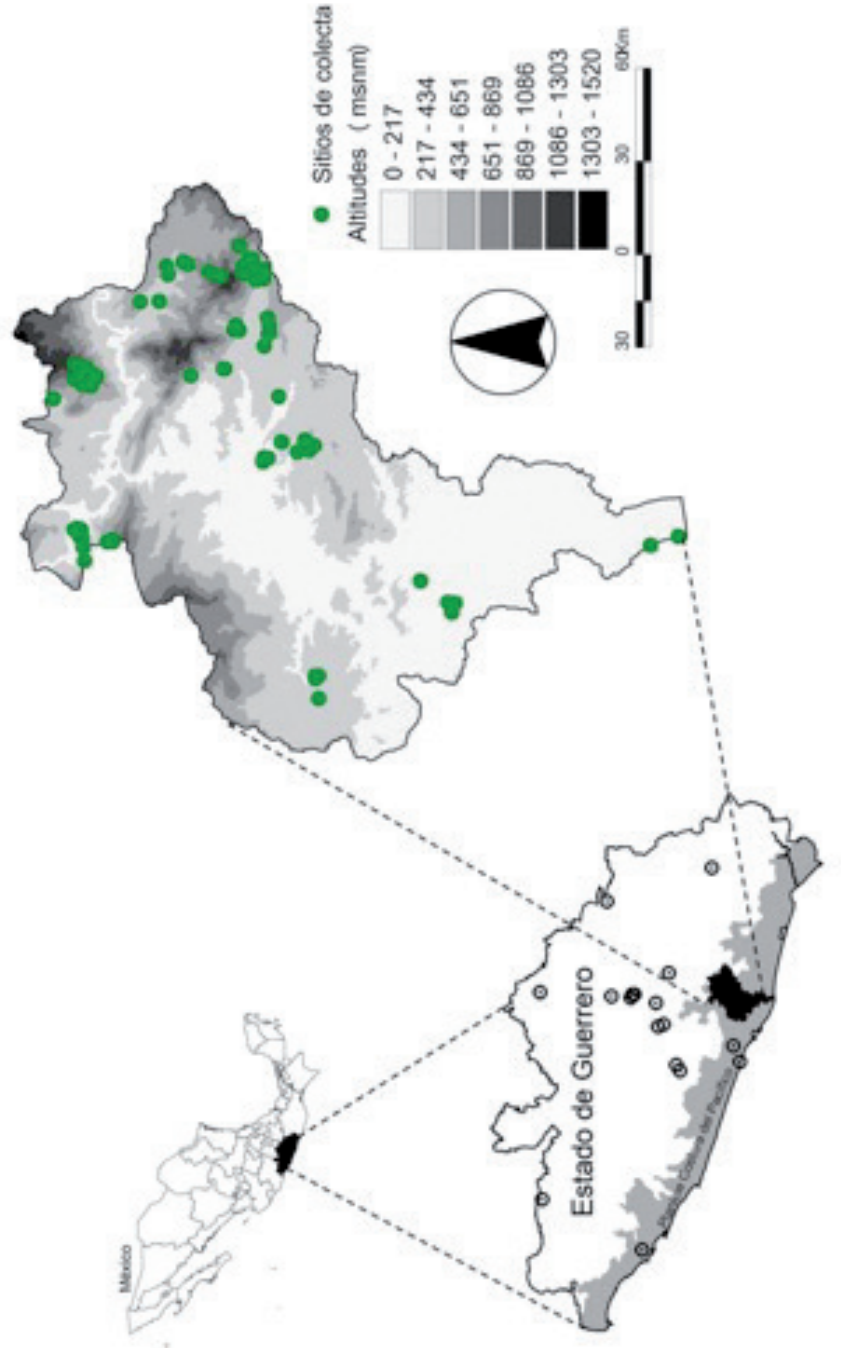

कू

응

등

금

유

巻

$\checkmark 8$

$\checkmark \stackrel{0}{0}$

을 인

范 ?

잉.

응으 을

ग

¿

을 으 ᄋ

즈 근

표

离

응

0

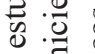

음 흠

Ðํㅡㄹ

*

$\overline{0}$

정.

뉸

क.

\&.

:응 을

]ี 즈

尚

-

ตั0 
Cuadro 1. Familias más representadas en la cuenca baja del río Papagayo, Guerrero.

\begin{tabular}{lcccc}
\hline Familias & $\begin{array}{c}\text { Número de } \\
\text { especies }\end{array}$ & $\begin{array}{c}\text { Proporción del } \\
\text { total de especies } \\
\mathbf{( \% )}\end{array}$ & $\begin{array}{c}\text { Número de } \\
\text { géneros }\end{array}$ & $\begin{array}{c}\text { Proporción del } \\
\text { total de géneros } \\
\mathbf{( \% )}\end{array}$ \\
\hline Fabaceae & 43 & 21.1 & 30 & 18.4 \\
Poaceae & 15 & 7.4 & 12 & 7.4 \\
Asteraceae & 10 & 4.9 & 9 & 5.5 \\
Euphorbiaceae & 8 & 3.9 & 6 & 3.7 \\
Rubiaceae & 8 & 3.9 & 5 & 3.1 \\
Bignoniaceae & 6 & 2.9 & 5 & 3.1 \\
Boraginaceae & 5 & 2.5 & 3 & 1.8 \\
Tiliaceae & 5 & 2.5 & 4 & 2.5 \\
Cyperaceae & 4 & 2.0 & 2 & 1.2 \\
Lamiaceae & 4 & 2.0 & 2 & 1.2 \\
Sterculiaceae & 4 & 2.0 & 3 & 1.8 \\
Verbenaceae & 4 & 2.0 & 4 & 2.5 \\
Otras 61 & 88 & 43.1 & 78 & 47.9 \\
\hline
\end{tabular}

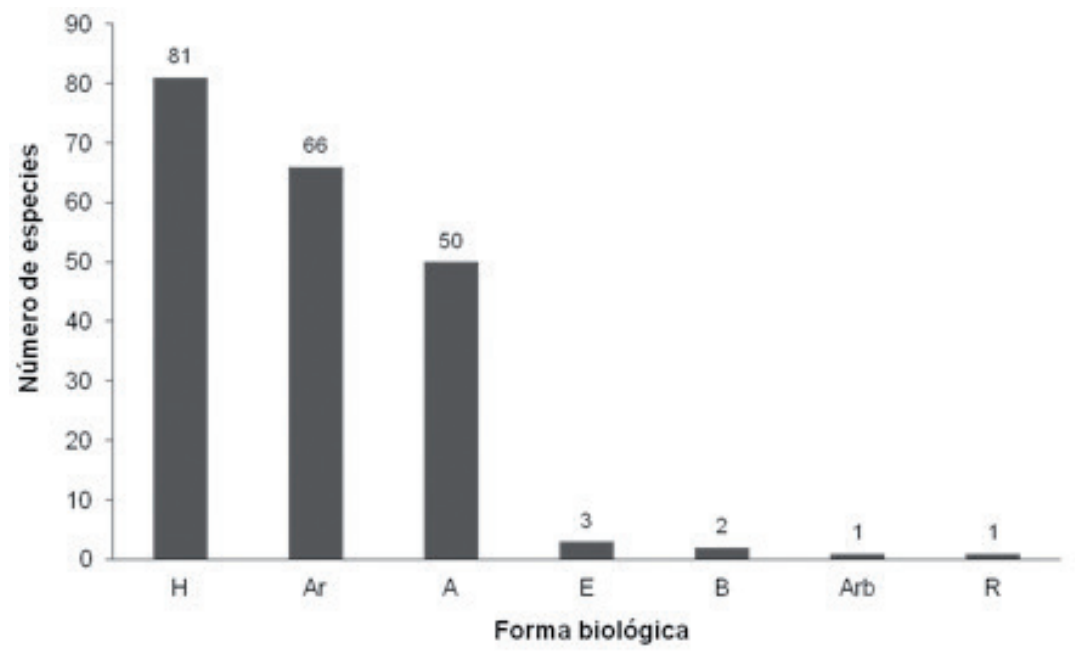

Fig. 2. Formas biológicas presentes en la cuenca baja del río Papagayo, Guerrero. $\mathrm{H}=$ Hierbas, $\mathrm{Ar}=$ arbustos, $\mathrm{A}=$ árboles, $\mathrm{E}=$ enredaderas, $\mathrm{B}=$ bejucos, $\mathrm{Arb}=$ arborescente, $\mathrm{R}=$ rastrera. 
Avicennia germinans (mangle negro), mientras que Rhizophora mangle (mangle rojo) fue la única especie que se encontró en la categoría de amenazada endémica.

\section{Tipos de vegetación}

De los 11 tipos de vegetación o asociaciones vegetales determinadas en el área de estudio (fig. 3), la SBC fue la que presentó la mayor riqueza (131 especies), seguido de la vegetación secundaria (83 especies), bosque de encino (56 especies), bosque de pino (30 especies), bosque de encino-pino (29 especies), pastizal (16 especies) y vege- tación en galería (16 especies; fig. 4). Por su parte, la selva mediana subcaducifolia, manglar, bosque de Curatella americana y tular, presentaron menos de seis especies (fig. 4). El mayor número de especies en riesgo se encontró en la SBC y la vegetación secundaria (cuadro 2).

\section{Selva baja caducifolia}

La SBC es la vegetación dominante en el área de estudio con el 32.96\% (405.06 km²), considerando tanto a las áreas conservadas como perturbadas (fig. 3). Se distribuye desde los 246 hasta los $1040 \mathrm{~m}$ de altitud. Se encuentra constituido por un estrato arbóreo

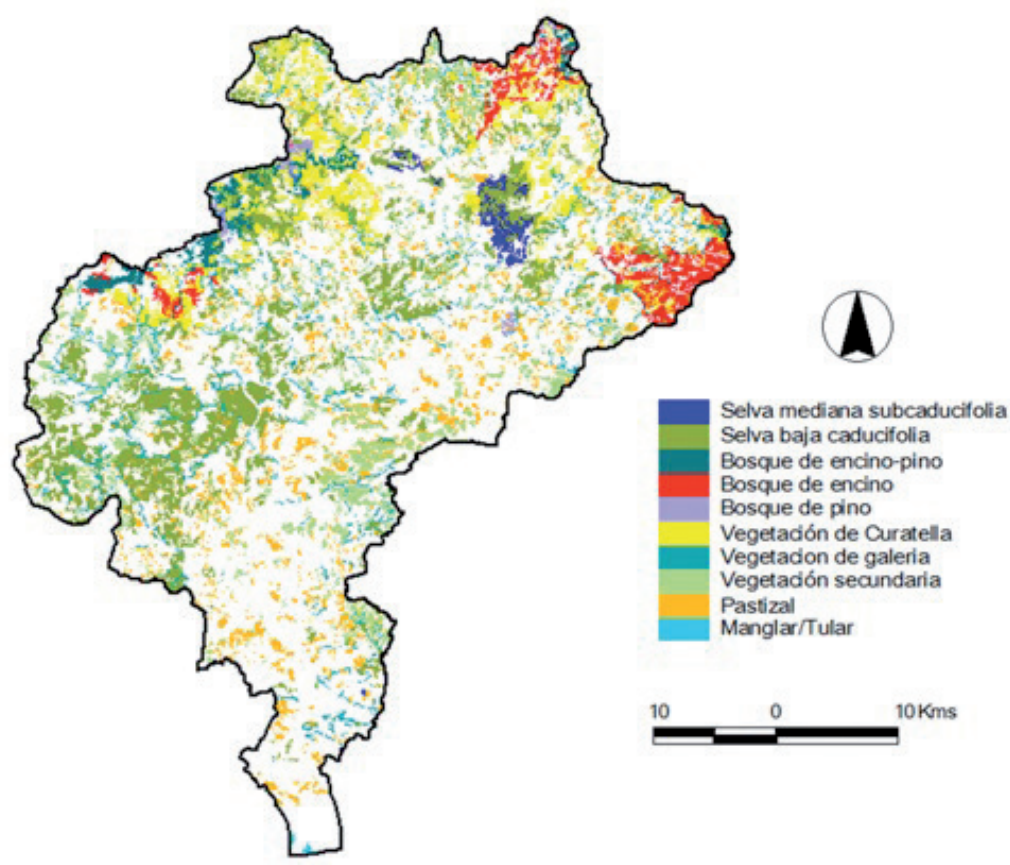

Fig. 3. Distribución espacial de los tipos de vegetación en la cuenca baja del río Papagayo, Guerrero. Los espacios en blanco representan las áreas de agricultura, zonas urbanas y cuerpos de agua. Este mapa fue elaborado con ayuda de imágenes satelitales Lansat y Quickbird, cartografía vectorial de INEGI (escala 1:50,000) y recorridos de campo. 
donde algunas de las especies más representativas son: Annona diversifolia, Spondias purpurea, Bursera excelsa, Sapium macrocarpum, Plumeria rubra, Tabebuia chrysantha, Diospyros riojae, Cordia elaeagnoides y Tabebuia palmeri. En el estrato arbustivo, las especies características son: Ageratum corymbosum, Salvia elegans, Ardisia compressa, Psidium sartorianum y Vitex mollis y en el herbáceo: Melochia tomentella, Turnera ulmifolia, Cosmos crithmifolius y Barleria oenotheroides, entre otras.

\section{Pastizal}

Esta vegetación se distribuye en toda el área de estudio en forma de manchones en las partes bajas y altas de los cerros, en altitudes que van de 170 a 1040 m.s.n.m. (fig. 3). Esta comunidad vegetal representa el $10.77 \%$ $\left(132.30 \mathrm{~km}^{2}\right)$ del total del área de estudio. Las áreas con este tipo de vegetación se clasifican en natural e inducido. El pastizal natural está dominado por especies herbáceas de pastos o "zacates", principalmente de la familia Poaceae (Gramineae). Éstos se desarrollan de manera natural en las áreas abiertas y se distribuyen en toda el área de estudio en forma de manchones en las partes bajas y altas de los cerros. Las principales especies que se establecen son Muhlenbergia tenuifolia, Paspalum sparsum, Setaria parviflora y Panicum trichoides.

El pastizal inducido es usado con fines pecuarios a partir de la destrucción o alteración de tipos de vegetación como los bosques de encino y selva baja caducifolia. Esta comunidad vegetal se reconoce por la presencia de pastos introducidos como Panicum maximun, Andropogon gayanus, Hyparrhenia rufa, Cynodon dactylon y Rhynchelytrum repens. Estos pastizales han sido inducidos por los diferentes cambios en el uso del suelo, por abandono de áreas de cultivo, incendios o para pastoreo. Se encuentran en pequeños parches aislados distribuidos de manera uniforme en casi toda el área de estudio, incluyendo las partes altas en donde se desarrolla el rasca (Curatella americana), aunque en menor proporción, y asociados principalmente al bosque de encino y selva baja caducifolia, ambos con diferentes grados de perturbación.

\section{Bosque de encino}

Este tipo de vegetación cubre una superficie del $4.32 \%\left(53.10 \mathrm{~km}^{2}\right)$, el cual se encuentra en altitudes entre los 693 a 1386 m (fig. 3). Está constituido por especies arbóreas predominantes como: Quercus castanea, Quercus peduncularis, Quercus candicans y Genipa americana. En el estrato arbustivo predominan Curatella americana, Byrsonima crassifolia, Vernonia patens, Astianthus viminalis, Croton reflexifolius, Desmodium sp. y Acacia farnesiana. El estrato herbáceo está caracterizado por la presencia de Zornia thymifolia, Eryngium ghiesbreghtii, Zinnia peruviana, Cyperus laxus, Paspalum fasciculatu y Gomphrena serrata.

\section{Vegetación en galería}

Esta vegetación cubre una superficie de $17.17 \mathrm{~km}^{2}(1.40 \%)$, y se desarrolla en los márgenes de los ríos Papagayo y el Omitlán, así como los ríos estacionales de Chautipa y el Potrero Oriental, a una altitud de $70 \mathrm{~m}$ de altitud (fig. 3). Fisonómicamente este tipo de vegetación está constituido por especies arbóreas representativas como Salix humboldtiana y Astianthus viminalis. En el estrato arbustivo se tiene a Clidemia hirta, Bixa orellana y Casearia obovata, y en el herbáceo a Morella lindeniana, Hymenocallis sp. y Heliotropium indicum, entre otras. 
Cuadro 2. Especies vegetales en alguna categoría de riesgo en los tipos de vegetación de la cuenca baja del río Papagayo, Guerrero. $\mathrm{SBC}=$ selva baja caducifolia, $\mathrm{VS}=$ vegetación secundaria, $\mathrm{VG}=$ vegetación en galería, $\mathrm{P}=$ pastizal, $\mathrm{M}=$ manglar.

\begin{tabular}{llcc}
\hline \multicolumn{1}{c}{ Familia } & \multicolumn{1}{c}{ Especies } & Vegetación & Categoría de riesgo \\
\hline Asteraceae & Zinnia violaceae & VS, P & amenazada \\
Bignoniaceae & Tabebuia chrysantha & SBC, VS, & amenazada \\
Bignoniaceae & Tabebuia palmeri & VG, SBC & amenazada \\
Clusiaceae & Calophyllum brasiliense & VG & amenazada \\
Chrysobalanaceae & Licania arborea & SBC, VS & amenazada \\
Combretaceae & Laguncularia racemosa & $\mathrm{M}$ & amenazada \\
Euphorbiaceae & Sapium macrocarpum & $\mathrm{SBC}$ & amenazada \\
Fabaceae & Peltogyne mexicana & $\mathrm{SBC}$ & amenazada \\
Rhizophoraceae & Rhizophora mangle & $\mathrm{M}$ & amenazada \\
Sapotaceae & Mastichodendron capiri & VG, SBC, VS & amenazada \\
Verbenaceae & Avicennia germinans & $\mathrm{M}$ & amenazada
\end{tabular}

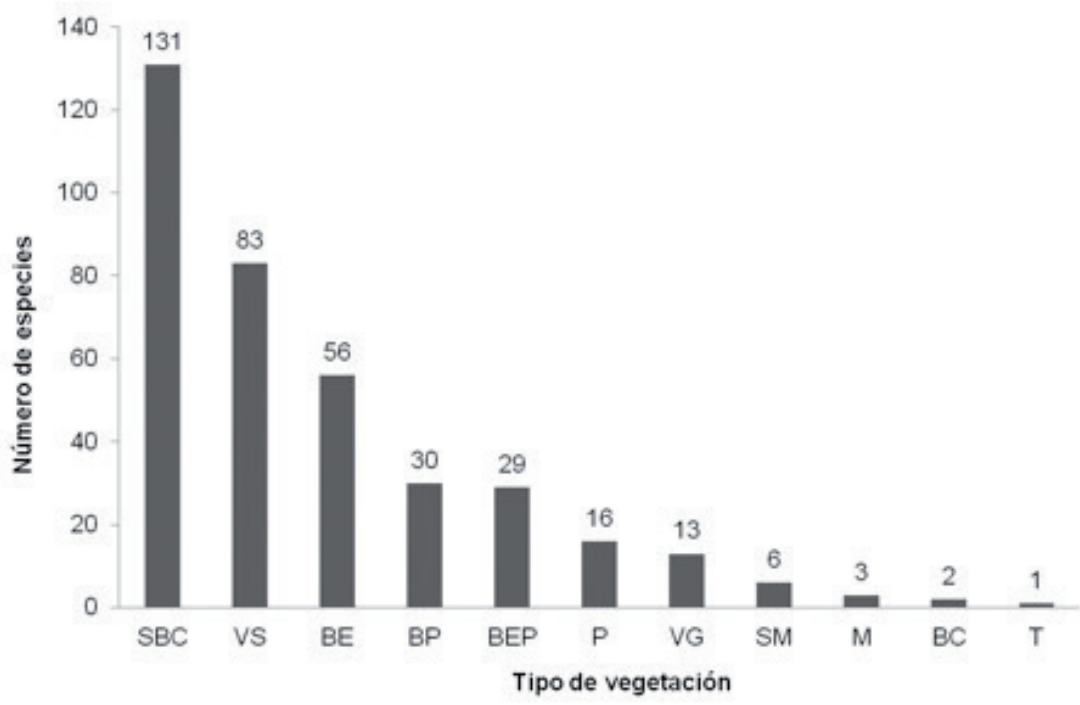

Fig. 4. Riqueza florística por tipo de vegetación en la cuenca baja del río Papagayo, Guerrero. $\mathrm{SBC}=$ selva baja caducifolia, $\mathrm{BE}=$ bosque de encino, $\mathrm{VS}=$ vegetación secundaria, $\mathrm{VG}=$ vegetación en galería, $\mathrm{BEP}=$ bosque de encino-pino, $\mathrm{P}=$ pastizal, $\mathrm{BP}=$ bosque de pino, $\mathrm{M}=$ manglar, $\mathrm{BC}=$ bosque de Curatella americana, $\mathrm{SMS}=$ selva mediana subcaducifolia,

$$
\mathrm{T}=\text { tular. }
$$




\section{Bosque de pino}

En la zona de estudio este tipo de vegetación está representado en pequeños parches ubicados en los límites norteños del área a $1040 \mathrm{~m}$ de altitud (fig. 3). Abarca una superficie de $6.36 \mathrm{~km}^{2}(0.52 \%)$. Este tipo de vegetación está constituido principalmente por Pinus oocarpa, asociado a algunas especies arbustivas como: Agarista mexicana Acacia farnesiana, Vernonia patens, Arbutus xalapensis e individuos aislados de Curatella americana. Las herbáceas que predominan son: Astianthus viminali, Echeandia flexuosa, Zinnia peruviana y Lobelia occidentalis.

\section{Bosque de encino-pino}

Esta comunidad vegetal cubre una superficie de $5.32 \mathrm{~km}^{2}$, que representa el $0.43 \%$ de la superficie total (fig. 3). Se encuentra representada por pequeños manchones principalmente al norte del área de estudio en altitudes que van de los 693 a los $1040 \mathrm{~m}$. Las especies presentes en el estrato arbóreo son: Quercus candicans, Q. castanea y Pinus oocarpa principalmente. Otras especies de tipo arbustivo son Vernonia patens, Galactia sp, Bunchosia palmeri y Coccoloba barbadensis. En el estrato herbáceo predominan Margaritaria nobilis, Eryngium ghiesbreghtii, Cosmos crithmifolius, Panicum trichoides y Stachys coccinea. En la comunidad de Xolapa, al sur del área de estudio, se encuentra también un pequeño manchón a una altitud de 780 metros.

\section{Selva mediana subcaducifolia}

Se encuentra ubicada en la parte media alta del área de estudio, principalmente en las cañadas o sitios de difícil acceso como los cerros Las Piñas y Alto Tepeguaje, en altitudes que van de los 346 a los $1040 \mathrm{~m}$. Este tipo de vegetación cubre una superficie de
$4.42 \mathrm{~km}^{2}(0.36 \%)$. Entre las especies arbóreas predominantes se encuentran Peltogyne mexicana, Cordia alliodora, Heliocarpus occidentalis y Pterocarpus acapulcensis. En el estrato arbustivo se encuentran principalmente Helicteres guazumifolia, Caesalpinia eriostachys y Lysiloma acapulcense (fig. 3).

\section{Manglar}

Esta vegetación se establece a una altitud promedio de 4 m.s.n.m., cuya superficie es de $0.60 \mathrm{~km}^{2}(0.05 \%)$. Se encuentra representada por pequeños manchones que se localizan cerca de la localidad de Lomas de Chapultepec hasta la desembocadura del río Papagayo en el sur del área de estudio (fig. 3). La especie predominante en las partes más húmedas es el mangle blanco (Laguncularia racemosa), y en las partes de menor humedad el mangle negro (Avicennia germinans). Se encuentran también algunos individuos aislados de mangle rojo (Rhizophora mangle).

\section{Tular}

Se encuentra representado por un pequeño manchón en una superficie de $0.03 \mathrm{~km}^{2}$ $(0.003 \%)$, ubicada en la desembocadura del río Papagayo (fig. 3). Esta vegetación está constituida principalmente por una sola especie de tule (Schoenoplectus sp), de aproximadamente $1 \mathrm{~m}$ de altura.

\section{Vegetación secundaria}

Es una comunidad derivada por la eliminación de la selva baja caducifolia primaria de las partes medias bajas de las áreas cerriles y comprende una superficie de $268.67 \mathrm{~km}$ (21.87\%) (fig. 3). Su extensión es significativa, ya que se encuentra casi en la misma proporción que la selva baja caducifolia perturbada, sobre todo, por las actividades antropogénicas (desmontes para el estable- 
cimiento de áreas agrícolas, ganaderas y tala selectiva de especies vegetales). Su composición florística está constituida por árboles cuyas especies características son: Licania arborea, Diospyros riojae, Annona diversifolia, A. squamosa. Entre las arbustivas: Caesalpinia pulcherrima, Cassia grandis, Krameria cuspidata, Acacia cochliacantha y Marina sp. En el estrato herbáceo Gomphrena serrata, Tithonia tubiformis y Crotalaria acapulcensis.

\section{Asociación de Curatella americana}

Es una vegetación derivada principalmente por la perturbación del bosque de encino, pino y en menor proporción de la SBC. No se considera dentro de la clasificación de vegetación secundaria por ser una vegetación fisonómicamente ya definida y establecida desde hace aproximadamente 25 años (fig. 3). Las áreas de este tipo de vegetación se ubican en altitudes que van de los 500 a los 1040 m.s.n.m., al noreste de Pochotillo se encuentra asociado con el bosque de encino. Cubre alrededor de $26.77 \mathrm{~km}^{2}$ (2.18\%). Está compuesto principalmente por la especie rasca (Curatella americana) y en menor proporción por especies de nanche (Byrsonima crassifolia).

\section{DISCUSIÓN}

La riqueza florística del área de estudio se podría considerar como importante bajo el argumento de que se obtuvo el $4.4 \%$ del total de especies de Magnoliophyta que se estiman para el estado de Guerrero (Villaseñor, 2003), en una región que representa el $2 \%$ de la superficie estatal. Asimismo, en la cuenca baja del río Papagayo se obtuvo el $19.5 \%$ de las plantas vasculares que Peralta-Gómez et al. (2000) documentaron para la región de la Costa Grande de Guerrero, y cuya super- ficie comprende alrededor de $2500 \mathrm{~km}^{2}$. No obstante, el número de especies obtenidas en este estudio es menor al de otras regiones con similitud en las comunidades vegetales y que presentan incluso menor extensión territorial. Por ejemplo, en la región de Zimatán en Oaxaca cuya superficie equivale a poco menos del $60 \%\left(713 \mathrm{~km}^{2}\right)$ de lo que representa la cuenca del Papagayo (Salas-Morales et al., 2003), se registraron 1384 especies. Cifra también superior fue la reportada para el Parque Nacional Huatulco con 736 especies en $119 \mathrm{~km}^{2}$ (Salas-Morales et al., 2007). En el Parque Ecológico La Vainilla en las cercanías con Zihuatanejo (Gallardo, 1996), se registraron 428 especies en 3.44 $\mathrm{km}^{2}$, que abarcaron tres tipos de vegetación (bosque tropical caducifolio, subcaducifolio y de galería).

Una de las razones de que en la cuenca baja del río Papagayo se hayan registrado menos especies comparado con otros sitios, puede ser resultado de la degradación antrópica que ha venido sufriendo esta región. Las cuencas costeras en general, y particularmente la del Papagayo, sufren de un fuerte proceso de colonización por parte de complejos turísticos y desarrollos urbanos (García-Romero et al., 2008). En consecuencia, se incrementa la degradación en la cobertura de la vegetación y disminuye la composición florística. Así también, debido a que los muestreos estuvieron mayormente enfocados a la SBC, es posible que especies de otros ambientes no se hayan registrado. El análisis de acumulación de especies reveló además que la riqueza obtenida en la $\mathrm{SBC}$ del área de estudio es similar a la esperada.

Con base en lo antes planteado, es factible indicar que el inventario de la flora de la cuenca baja del río Papagayo se podría 
incrementar con la adición de especies de ambientes poco muestreados (e. g. selva mediana). Por tal razón, no se puede asegurar que el inventario florístico de la región está completo. Sin embargo, no por ello el listado obtenido deja de ser relevante, sobre todo si se considera el poco desarrollo de estudios florísticos a lo largo de la costa del Pacífico guerrerense (Peralta-Gómez et al., 2000), que además presenta varios ambientes de importancia ecológica.

Como se esperaba, las Magnoliopsida fueron el grupo dominante en el área de estudio con el $86.8 \%$ del total. A nivel nacional e incluso mundial, las dicotiledóneas constituyen el grupo más importante en cuanto a riqueza florística, al grado que de las 15 familias con mayor número de especies en México, 11 pertenecen a este complejo (Villaseñor, 2003). Por su parte, las familias botánicas con mayor número de especies fueron Fabaceae, Poaceae, Asteraceae, Euphorbiaceae y Rubiaceae, aspecto consistente con lo encontrado en otras regiones dentro de la Planicie Costera (Gallardo, 1996; Peralta-Gómez et al., 2000), y en general del país con predominancia de SBC (Castillo et al., 2007). Estas familias han sido mencionadas como de importancia en los ecosistemas neotropicales tanto por su riqueza, dominancia y amplia distribución (Rico y Fonseca, 2005; Dorado et al., 2005; Huber et al., 2006). De manera particular, el mayor número de especies de las Fabaceae, Poaceae y Asteraceae pudiera también estar asociado a que los tipos de vegetación encontrados en el área de estudio han sufrido reducciones sustanciales en sus áreas naturales, producto de perturbaciones por actividades agropecuarias y la corta selectiva de especies vegetales. Especies de estas familias se desarrollan o adaptan a ciertas condiciones de perturbación (Pruski y Sancho, 2009; Leirana et al., 2009), razón por la cual la fisonomía del área de estudio está dada principalmente por hierbas de las familias Poaceae y Asteraceae, y arbustos que provienen de las Fabaceae.

Por otro lado, resulta interesante el hecho de que si bien en la cuenca del Papagayo la vegetación predominante es $\mathrm{SBC}$, varias familias que son típicas de estos ambientes como las Burseraceae o Cactaceae (Rzedowski et al., 2005; Avila et al., 2010; Almazán-Núñez et al., 2012), estuvieron poco representadas en el área de estudio. En particular, la distribución de la mayoría de especies de estas familias está confinada a la cuenca del Balsas (Fernández et al., 1998; Rzedowski et al., 2005). Las diferencias en el recambio de varios de los taxones que se distribuyen en las selvas bajas pueden ser explicadas por factores microclimáticos, topográficos y edáficos locales, como lo sugirieron Murphy y Lugo (1998), al analizar la diversidad beta de las selvas bajas de varias regiones del planeta.

Se enlistaron nueve especies en la categoría de amenazadas según la NOM-059-SEMARNAT-2010, varias de las cuales se desarrollan en ambientes sometidos continuamente a presiones antropogénicas (e. g., Zinnia violacea, Tabebuia chrysantha). Además de que varias de estas especies vegetales son selectivamente cortadas para usos locales diversos (i.e., Tabebuia chrysantha, Licania arborea). Durante los recorridos de campo se pudieron observar no más de cinco individuos de Licania arborea, algo que coincide con lo observado para otras regiones de México (López-Patiño et al., 2012). Estudios poblaciones con esta y otras especies deben realizarse para determinar su 
estatus. En el caso de Rizophora mangle, una especie endémica a México, su conservación es imperativa ya que los manglares en general se han visto desplazados y por tanto se han reducido extensiones considerables (CONABIO, 2009).

La SBC es la vegetación predominante en el área de estudio y también la de mayor número de especies. Aunque en el mapa sobre los tipos de vegetación no se plasma la superficie conservada o perturbada para cada vegetación, es pertinente indicar que la amplia extensión de vegetación secundaria en la zona es consecuencia de los constantes cambios en el uso del suelo de la SBC y en menor proporción del resto de los hábitats. Es común observar parches con diferentes niveles de sucesión de este tipo de vegetación, patrón recurrente en las selvas bajas caducifolias de Mesoamérica (Quesada et al., 2009). Algunas áreas con vegetación de pino, encino y selva mediana subcaducifolia se pueden considerar en buen estado de conservación como las ubicadas en la porción norte (áreas montañosas). Otras son de especial interés como las que comprenden el manglar y tular, ya que son ecosistemas únicos y de poca superficie en el área, y además representan sistemas naturales que sirven de refugio y anidación a la fauna silvestre. Además por ser ecosistemas frágiles por su ubicación (línea costera), están sujetas a la presión antropogénica como la destrucción del hábitat, sobreexplotación, así como la ampliación de los asentamientos humanos. A nivel nacional, Guerrero es la única entidad con humedales costeros cuyos manglares no cuentan con superficie bajo protección federal y/o estatal (CONABIO, 2009), por lo que su conservación, aunado a la de otros ambientes, resulta necesaria.

\section{CONCLUSIONES}

Los resultados de este estudio permiten concluir que el inventario florístico obtenido para la cuenca baja del río Papagayo aun no está completo. La gran extensión territorial que abarca, además de las asociaciones vegetales que allí se establecen, sugieren la posibilidad de encontrar un mayor número de especies, particularmente en ambientes poco muestreados. A nivel de familias, el mayor número de especies se presentó en las Fabaceae, Poaceae, Asteraceae, Euphorbiaceae y Rubiaceae, las cuales aportan poco más del $40 \%$ de la riqueza total, resultado que parece coincidir con regiones donde predomina la selva baja caducifolia. Nueve de las 204 especies se encuentran en la categoría de amenazadas por la NOM-059-SEMARNAT-2010. Varias de estas especies deben ser consideradas para generar estudios que conlleven el manejo sustentable de las mismas. Particularmente, porque en los sitios donde fueron colectadas (SBC, manglar), han perdido buena parte de su vegetación original, debido a las actividades antropogénicas.

En orden de importancia por la superficie que ocupan los tipos de vegetación en la zona de estudio se encuentra la selva baja caducifolia, pastizal, bosque de encino, vegetación de Curatella americana, vegetación en galería, bosque de pino, bosque de encino-pino, selva mediana subcaducifolia, manglar y tular. La vegetación secundaria derivada de la selva baja caducifolia también presenta una amplia superficie producto de la perturbación que han sufrido los ecosistemas naturales del área. Esta última comunidad vegetal junto con la selva baja caducifolia, la vegetación en galería, y los bosques de encino y pino son las que mayor riqueza florística presentaron. 


\section{AGRADECIMIENTOS}

A las doctoras Nelly Diego Pérez y Rosa María Fonseca, así como a todo el personal del Laboratorio de Plantas Vasculares de la UNAM por el apoyo en la identificación de los ejemplares botánicos. A la Comisión Federal de Electricidad por el apoyo económico para las salidas de campo y a diversos estudiantes de la licenciatura en biología de la Universidad Autónoma de Guerrero que apoyaron en el trabajo de campo.

\section{LITERATURA CITADA}

Almazán, A., y V. Sorani, 2005. “Programa de Ordenamiento Ecológico Territorial, de la zona de Influencia del P.H. La Parota, Guerrero". Reporte Técnico Final. Comisión Federal de Electricidad. Acapulco, Guerrero, México.

Almazán-Núñez, R.C.; M.C. Arizmendi, L. Eguiarte, y P. Corcuera, 2012. "Changes in composition, diversity and structure of woody plants in successional stages of tropical dry forest in southwest Mexico". Rev. Mex. Biodiv., 83(4): 1096-1109.

Ávila, P., A. Sánchez-González y C. Catalán, 2010. "Estructura y composición de la vegetación del Cañón del Zopilote, Guerrero, México". Rev. Chapingo, Ser. Cienc. Forest. Amb., 16(2): 119-138.

Carreto-Pérez B.E. y A. Almazán-Juárez, 2004. "Vegetación en la laguna de Tuxpan y alrededores". 1-32 pp. En: Diego-Pérez, N. y R.M. Fonseca (Eds.). Estudios florísticos en Guerrero. Num. 14. Facultad de Ciencias, UNAM. México, DF.
Castillo-Campos, G., P. Dávila y J.A. Zavala, 2007. "La selva baja caducifolia en una corriente de lava volcánica en el centro de Veracruz: lista florística de la flora vascular". Bol. Soc. Bot. Méx., 80: 77-104.

Catalán-Heverástico, C.; L. López-Mata y T. Terrazas, 2003. "Estructura, composición florística y diversidad de especies leñosas en un bosque mesófilo de montaña de Guerrero, México". An. Inst. Biol. UNAM, Serie Botánica 74: 209-230.

Challenger, A., 1998. Utilización y conservación de los ecosistemas terrestres de México: pasado, presente y futuro. CONABIO, Instituto de Biología-UNAM, agrupación Sierra Madre. México, DF. 847 pp.

Chazdon, R.L.; R.K. Colwell, J.S. Denslow y M. Guariguata. 1998. "Statistical estimation of species richness of woody regeneration in primary and secondary rainforest of northeastern Costa Rica". 185-309 pp. En: F. Dallmeier y J. Comiski (Eds.). Forest biodiversity in North, Central, and South America and the Caribbean: research and monitoring. Parthenon, Paris.

Colwell, R.K., 2006. EstimateS: statistical estimation of species richness and shared species from samples. Version 8. User's guide and application published at: http://viceroy.eeb.uconn.edu/ estimates.

CONABIO, 2009. Manglares de México: extensión y distribución. $2^{\mathrm{a}}$ ed. Comisión Nacional para el Conocimiento 
y Uso de la Biodiversidad. México, DF. 99 pp.

Cronquist, A., 1981. An Integrated System of Classification of Flowering Plants. Columbia University Press. New York. $1262 \mathrm{pp}$.

De-Nova A., R. Medina, J.C. Montero, A. Weeks, J.A. Rosell, M.E. Olson, L.E. Eguiarte y S. Magallón, 2012. "Insights into the historical construction of species-rich Mesoamerican seasonally dry tropical forest: the diversification of Bursera (Burseraceae, Sapindales)". New Phytologist, 193: 276-287.

Diego-Pérez, N., 2000. "Lagunas Playa Blanca, El Potosí, Salinas del Cuajo y zonas circundantes". 1-35 pp. pp. En: Diego-Pérez, N. y R.M. Fonseca (Eds.). Estudios Florísticos en Guerrero. Núm. 7. Facultad de Ciencias, UNAM. México, DF.

Diego-Pérez, N. y G. Calderón de Rzedowski, 2004. "Un nuevo género de Cruciferae (Brassicaceae) del estado de Guerrero, México". Acta Bot. Mex., 68: 73-79.

Diego-Pérez N., S. Peralta-Gómez y B. Ludlow-Wiechers, 2001. "El Jilguero, Bosque Mesófilo de Montaña". 1-42 pp. En: Diego-Pérez, N. y R.M. Fonseca (Eds.). Estudios Florísticos en Guerrero. Núm. 7. Facultad de Ciencias, UNAM. México, DF.

Dorado, O., D.M. Arias, R. Ramírez y M. Sousa, 2005. Leguminosas de la Sierra de Huautla. CONABIO, UAEM. México. 176 pp.
Fernández, R., C. Rodríguez, M.L. Arreguín y A. Rodríguez. 1998. "Listado florístico de la cuenca del río Balsas, México". Polibotánica, 9: 1-151.

Fonseca, R.M., y L. Lozada, 1993. "Laguna de Coyuca". 1-23 pp. En: Diego-Pérez, N. y R.M. Fonseca (Eds.). Estudios florísticos en Guerrero. Num. 1. Facultad de Ciencias, UNAM. México, DF.

Gallardo, C., 1996. "Parque Ecológico La Vainilla, Zihuatanejo, Guerrero". 1-61 pp. En: Diego-Pérez, N. y R.M. Fonseca (Eds.). Estudios florísticos en Guerrero. Num. 8. Facultad de Ciencias, UNAM. México, DF.

García-Romero, A., K.I. Mendoza y L. Galicia, 2005. "Valoración del paisaje de la selva baja caducifolia en la cuenca baja del río Papagayo (Guerrero), México". Inv. Geo. Bol. Inst. Geo. UNAM 56: 77-100.

Golubov, J., M.C. Mandujano y F. Mandujano, 2005. "Diversidad alfa y beta en Opuntia y Agave". 221-230 pp. En: Halffter, G., J. Soberón, P. Koleff y A. Melic (Eds.). Sobre diversidad biológica: el significado de las diversidades alfa, beta y gamma. Monografías Tercer Milenio, Sociedad Entomológica Aragonesa, Zaragoza.

Huber, O., R. Duno de Stefano, G. Aymard y R. Riina, 2006. "Flora and vegetation of the Venezuelan Llanos: a review". 87-112 pp. En: Pennington, R., J. Ratter y G. Lewis. Neotropical savannas and seasonally dry tropical forests: plant diversity, biogeography and conservation. CRC Press, Florida, USA. 
Jiménez, J., y M. Martínez, 2000. “Especie nueva de Jatropha (Euphorbiaceae) del estado de Guerrero, México". An. Inst. Biol. UNAM, Serie Botánica. 71: 35-38.

Leirana-Alcocer, J., S. Hernández-Betancourt, L.H. Salinas-Peba y L. Guerrero-González, 2009. "Cambios en la estructura y composición de la vegetación relacionados con los años de abandono de tierras agropecuarias en la selva baja caducifolia espinosa de la Reserva de Dzilam, Yucatán". Polibotánica, 27: 53-70.

López-Patiño, E.J., J.A. López-Sandoval, A.S. Beltrán-Retis y L.I. Aguilera-Gómez, 2012. "Composición de la Flora arbórea en el Área Natural Protegida Tenancingo-Malinalco-Zumpahuacán, Estado de México, México". Polibotánica, 34: 51-98

Lot, A., y F. Chiang, 1986. Manual de Herbario: administración y manejo de colecciones, técnicas de recolección y preparación de ejemplares botánicos. Consejo Nacional de Ciencia y Tecnología. México, DF. 142 pp.

Lozada, L., 1994. "Laguna de Mitla". 1-44 pp. En: Diego-Pérez, N. y R.M. Fonseca (Eds.). Estudios Florísticos en Guerrero. Núm. 2. Facultad de Ciencias, UNAM. México, DF.

Matteucci, S.D., y A. Colma, 1982. Metodología para el estudio de la vegetación. Serie Biología.

Monografía 22. Secretaría General de la Organización de los Estados Americanos y Programa Regional de Desarrollo Científico y Tecnológico. Washington, DC. 163 pp.

Meza, L. y J. López, 1997. "Vegetación y mesoclima de Guerrero". 1-53 pp. En: Diego-Pérez, N. y R.M. Fonseca (Eds.). Estudios Florísticos en Guerrero. Núm. 7. Facultad de Ciencias, UNAM. México, DF.

Miranda, F. y E. Hernández X., 1963. "Los tipos de vegetación de México y su clasificación". Bol. Soc. Bot. Méx., 28: 29-179.

Mittermeier, R.A. y C. Goettsch de Mittermeier, 1992. "La importancia de la diversidad biológica de México". 63-73 pp. En: Sarukhán, J. y R. Dirzo (Eds.). México ante los retos de la biodiversidad. CONABIO. México, DF.

Moreno, N.P., 1984. Glosario botánico ilustrado. Continental. México, DF. $300 \mathrm{pp}$.

Murphy, P.G., y A.E. Lugo, 1986. "Ecology of tropical dry forest". Ann. Rev. Ecol. Syst. 17: 67-88.

Oseguera-Carrasco, J., y C.J. Mancilla, 1986. "Identificación taxonómica de especies dominantes de la flora de la Isla La Roqueta, Acapulco, Guerrero". Tesis de licenciatura, Unidad Académica de Ciencias Químico-Biológicas. Chilpancingo, Guerrero, México. 244 pp.

Pennington, T.D. y J. Sarukhán, 2005. Arboles tropicales de México. Manual para la identificación de las principa- 
les especies. $3^{\mathrm{a}}$. ed. UNAM-Fondo de Cultura Económica. México, DF.

Peralta-Gómez, S., N. Diego-Pérez y M. Gual-Díaz, 2000. Listados florísticos de México XIX. La Costa Grande de Guerrero. Instituto de Biología, UNAM. México, DF. 49 pp.

Pruski J.F. y Sancho G. 2004. "Asteraceae". En: Smith N., Mori S.A., Henderson A., Stevenson D.W. y Heald S.V. Eds. Flowering Plants of the Neotropics, pp. 33-39, Princeton University Press, Princeton.

Quesada, M., G.A. Sánchez-Azofeita, M. Álvarez-Añorve, K.E. Stoner, L. Avila-Cabadilla, J. Calvo-Alvarado, A. Castillo, M.M. Espírito-Santo, M. Fagundes, G.W. Fernandes, J. Gamon, M. Lopezaraiza-Mikel, B. Lawrence, L.P. Cerdeira, J.S. Powers, F. Neves, V. Rosas-Guerrero, R. Sayago y G. Sánchez-Montoya, 2009. "Succession and management of tropical dry forests in the Americas: review and new perspectives". Forest Ecol. and Manag. 258: 1014-1024.

Rico, M.L., y R.M. Fonseca. 2005. “Acacieae (Mimosaceae)". 1-56 pp. En: Diego-Pérez, N. y R.M. Fonseca (Eds.). Estudios Florísticos en Guerrero. Núm. 7. Facultad de Ciencias, UNAM. México, DF.

Reyes-García, T., F.S. Maradiaga-Ceceña, C. Catalán-Heverástico, P. Ávila-Sánchez y J. Jiménez-Hernández. 2012. "Flora leñosa del municipio de Cocula, Guerrero, México”. Polibotánica, 34: 21-49.
Rzedowski, J., 1991. "Diversidad y orígenes de la flora fanerogámica de México". Acta Bot. Méx., 14: 3-21.

Rzedowski, J., R. Medina y G. Calderón de Rzedowski, 2005. "Inventario del conocimiento taxonómico, así como de la diversidad y del endemismo regionales de las especies mexicanas de Bursera (Burseraceae)". Acta Bot. Mex., 70: 85-111.

Rzedowski, G.C. de, J. Rzedowski y colaboradores, 2005. Flora fanerogamica del Valle de México. Instituto de Ecología, A.C. y Comisión Nacional para el Conocimiento de Uso de la Biodiversidad. Patzcuaro, Michoacán. (Edición digital: INECOL 2010), 1406 pp.

Salas-Morales, S.H., A. Saynes-Vásquez y L. Schibli, 2003. "Flora de la costa de Oaxaca, México: Lista florística de la región de Zimatán”. Bol. Soc. Bot. Méx., 72: 21-58.

Salas-Morales, S.H., L. Schibli, A. Nava-Zafra y A. Saynes-Vásquez, 2007. "Flora de la costa de Oaxaca, México (2): Lista florística comentada del Parque Nacional Huatulco". Bol. Soc. Bot. Méx., 81: 103-132.

SEMARNAT, 2010. "Norma Oficial Mexicana NOM-059-SEMARNAT-2010: Protección Ambiental-Especies nativas de México de flora y fauna silvestres-Categorías de riesgo y especificaciones para su inclusión, exclusión o cambio-Lista de especies en riesgo". Diario Oficial de la Federación 30 de diciembre de 2010; Segunda Sección. México, D.F. 
Toledo, V., 1988. "La diversidad biológica de México". Ciencia y Desarrollo, 14: 17-30.

Toledo, V., J. Rzedowski y J. Villa-Lobos, 1997. "Regional overview: Middle America". 97-124 pp. En: Davis S.D., V.H. Heywood, O. Herrera-Macbryde, J. Villa-Lobos y A.C. Hamilton (Eds.). Centres of Plant Diversity. A Guide and Strategy for Their Conservation. Volume 3. The Americas. WWWF/ UICN. Cambridge, Reino Unido.

Valencia-Ávalos, S., R. Cruz-Durán, M. Martínez-Gordillo y J. Jiménez-Ramírez, 2011. "La flora del municipio de Atenango del Río, estado de Guerrero, México". Polibotánica, 32: 9-39.
Vargas, A. y A. Pérez, 1996. "Cerro Chiletepetl y alrededores". 1-49 pp. En: Diego-Pérez, N. y R.M. Fonseca (Eds.). Estudios Florísticos en Guerrero. Núm. 7. Facultad de Ciencias, UNAM. México, DF.

Villaseñor, J.L., 2003. "Diversidad y distribución de las Magnoliophyta de México". Interciencia, 28(3): 160-168.

Recibido: 18 noviembre 2013. Aceptado: 15 enero 2015. 
Apéndice 1. Lista de especies vegetales registradas en la cuenca baja del río Papagayo, Guerrero.

\begin{tabular}{l} 
Phylum/Clase/Familia/Nombre ci \\
\hline PHYLUM MAGNOLIOPHYTA \\
CLASE MAGNOLIOPSIDA \\
ACANTHACEAE
\end{tabular}

Barleria oenotheroides Dum. Cours.

hierba

SBC

AMARANTHACEAE

Gomphrena serrata Linnaeus

hierba

VS,BE,P

ANACARDIACEAE

Amphipterygium adstringens (Schltdl.) Standl.

árbol

$\mathrm{SBC}, \mathrm{BE}$

ANNONACEAE

Annona diversifolia Saff.

Annona squamosa L.

árbol

SBC,VS

árbol

SBC,VS

\section{ANACARDIACEAE}

Spondias purpurea $\mathrm{L}$.

árbol

SBC,VS

APIACEAE

Eryngium ghiesbreghtii Decne.

hierba

BE,BEP,BP

APOCYNACEAE

Plumeria rubra L.

árbol

$\mathrm{SBC}$

Rauvolfia tetraphylla $\mathrm{L}$.

arbusto

VG,SBC

ASCLEPIADACEAE

Polystemma guatemalense (Schltr.) W.D. Stevens

enredadera

SBC,BP

\section{ASTERACEAE}

Ageratum corymbosum Zuccagni

arbusto

SBC,BP

Cosmos crithmifolius Kunth

hierba

SBC,BP,BEP

Dahlia coccinea Cav.

hierba

BE, $P$

Montanoa Cerv.

arbusto

SBC

Sanvitalia procums Lam.

hierba

SBC, VS

Tagetes L.

hierba

$\mathrm{BE}, \mathrm{BP}$

Tithonia tubiformis (Jacq.) Cass.

hierba

VS,SBC

Vernonia patens Kunth

arbusto

SBC,BP,BE,BEP

Zinnia peruviana (L.) L.

hierba

$\mathrm{BE}, \mathrm{BP}$

Zinnia violacea Cav.

hierba

VS,P 
Apéndice 1. Continuación.

Phylum/Clase/Familia/Nombre científico

\section{BEGONIACEAE}

Begonia chivacoa Ziesenh.

\section{BIGNONIACEAE}

Astianthus viminalis (Kunth) Baill.

Pithecoctenium crucigerum (L.) A.H. Gentry

Crescentia alata Kunth

Tabebuia chrysantha (Jacq.) G. Nicholson

Tabebuia palmeri Rose

Tecoma stans (L.) Juss. ex Kunth

\section{BIXACEAE}

Bixa orellana $\mathrm{L}$.

\section{BOMBACACEAE}

Ceiba aesculifolia (Kunth) Britten \& Baker f. Pseudobombax ellipticum (Kunth) Dugand

\section{BORAGINACEAE}

Cordia dentata Poir.

Cordia alliodora (Ruiz \& Pav.) Oken

Cordia elaeagnoides DC.

Heliotropium indicum $\mathrm{L}$.

Ehretia latifolia DC.

\section{BURSERACEAE}

Bursera bipinnata (DC.) Engl.

Bursera excelsa (Kunth) Engl.

Bursera simaruba (L.) Sarg.

\section{CACTACEAE}

Opuntia tomentosa Salm-Dyck

\section{CARICACEAE}

Jacaratia mexicana A. DC.

\section{CECROPIACEAE}

Cecropia obtusifolia Bertol.

\section{Forma de crecimiento \\ Vegetación}

hierba

SBC

$\begin{array}{cc}\text { arbusto } & \text { SBC,BE,BP } \\ \text { enredadera } & \mathrm{SBC}, \mathrm{VS} \\ \text { arbusto } & \mathrm{SBC}, \mathrm{VS} \\ \text { árbol } & \mathrm{VS}, \mathrm{SBC} \\ \text { árbol } & \mathrm{VG}, \mathrm{SBC} \\ \text { arbusto } & \mathrm{BE}, \mathrm{SBC}, \mathrm{VS}\end{array}$

árbol

SBC

árbol

SBC, VS

árbol

SBC,VS

arbusto

SBC, VS

arbusto

$\mathrm{SBC}$

árbol

$\mathrm{SBC}$

hierba

VG,SBC

árbol

SBC

arbusto

SBC, VS

arbusto

SBC, VS

árbol

SBC,SM

arborescente

SBC, VS

árbol

SBC

árbol

VG,SBC,SM 
Apéndice 1. Continuación.

Phylum/Clase/Familia/Nombre científico

CAMPANULACEAE

Lobelia occidentalis McVaugh \& Huft

COMBRETACEAE

Laguncularia racemosa (L.) C.F. Gaertn.

\section{COCHLOSPERMACEAE}

Cochlospermum vitifolium (Willd.) Spreng.

\section{CLUSIACEAE}

Calophyllum brasiliense Cambess.

\section{CHRYSOBALANACEAE}

Licania arborea Seem.

\section{DILLENIACEAE}

Curatella americana $\mathrm{L}$.

\section{EBENACEAE}

Diospyros albens C. Pres1

Diospyros riojae Gómez Pompa

\section{ERICACEAE}

Agarista mexicana (Hemsl.) Judd

\section{EUPHORBIACEAE}

Cnidoscolus tubulosus (Müll. Arg.) I.M. Johnst.

Croton reflexifolius Kunth

Croton repens Schltdl.

Croton suberosus Kunth

Dalembertia populifolia Müll. Arg.

Jatropha curcas L.

Margaritaria nobilis L. f.

Sapium macrocarpum Müll. Arg.

\section{FABACEAE}

Acacia cochliacantha Humb. \& Bonpl. ex Willd. Acacia farnesiana (L.) Willd.

Acacia hindsii Benth.

\begin{tabular}{cc}
$\begin{array}{c}\text { Forma de } \\
\text { crecimiento }\end{array}$ & Vegetación \\
\hline hierba & BP,BE,BEP
\end{tabular}

arbusto

M

árbol

SBC, VS

árbol

VG

árbol

SBC, VS

SBC,BE,

arbusto $\mathrm{BC}, \mathrm{VS}$

árbol

SBC

árbol

VS,SBC

arbusto

BP

$\begin{array}{cc}\text { hierba } & \text { VS,SBC,BE } \\ \text { arbusto } & \text { SBC,BP,BE } \\ \text { hierba } & \text { BE,BP } \\ \text { hierba } & \text { SBC,SM } \\ \text { arbusto } & \text { SBC } \\ \text { arbusto } & \text { SBC,VS } \\ \text { arbusto } & \text { BEP,SBC } \\ \text { árbol } & \text { SBC }\end{array}$

arbusto

SBC, VS

arbusto

VG,BE,P,SBC

arbusto

VS 
Apéndice 1. Continuación.

\begin{tabular}{|c|c|c|}
\hline Phylum/Clase/Familia/Nombre científico & $\begin{array}{l}\text { Forma de } \\
\text { crecimiento }\end{array}$ & Vegetación \\
\hline Acaciella Britton \& Rose & arbusto & SBC, VS \\
\hline Andira inermis DC. & árbol & VG,SBC \\
\hline Apoplanesia paniculata C. Presl & arbusto & $\mathrm{SBC}$ \\
\hline Caesalpinia pulcherrima (L.) Sw. & arbusto & $\mathrm{VS}, \mathrm{VG}$ \\
\hline Caesalpinia eriostachys Benth. & árbol & $\mathrm{SM}, \mathrm{SBC}$ \\
\hline Cassia grandis L. f. & arbusto & VS,SBC \\
\hline Cassia hintonii Sandwith & árbol & $\mathrm{SBC}, \mathrm{VS}$ \\
\hline Crotalaria acapulcensis Hook. \& Arn. & hierba & VS,BP \\
\hline Crotalaria $\mathrm{L}$ & hierba & $\mathrm{BP}$ \\
\hline Chamaecrista nictitans (L.) Moench & hierba & $\mathrm{BE}, \mathrm{SBC}$ \\
\hline Chamaecrista Moench & rastrera & BEP \\
\hline Dalbergia L. f. & arbusto & VG \\
\hline Desmodium sp. Desv. & hierba & $\mathrm{BE}$ \\
\hline Entadopsis polystachya (L.) Britton & bejuco & $\mathrm{SBC}, \mathrm{P}$ \\
\hline Enterolobium cyclocarpum (Jacq.) Griseb. & árbol & SBC,SM,VS \\
\hline Galactia P. Browne & arbusto & BEP \\
\hline Gliricidia sepium (Jacq.) Kunth ex Walp. & árbol & $\mathrm{SBC}, \mathrm{VS}$ \\
\hline Haematoxylum brasiletto H. Karst. & arbusto & $\mathrm{SBC}, \mathrm{VS}$ \\
\hline Hymenaea courbaril L. & árbol & VG,SBC,VS \\
\hline Inga spuria Humb. \& Bonpl. ex Willd. & árbol & $\mathrm{SBC}, \mathrm{SM}$ \\
\hline Leucaena leucocephala (Lam.) de Wit & árbol & SBC,VS \\
\hline Lysiloma divaricata Hook. \& Jackson & árbol & SBC,VS \\
\hline Lysiloma acapulcense (Kunth) Benth. & árbol & $\mathrm{SBC}, \mathrm{VS}$ \\
\hline Lysiloma Benth. & árbol & SBC,VS \\
\hline Lysiloma Benth. & árbol & $\mathrm{SBC}, \mathrm{VS}$ \\
\hline Marina sp. Liebm. & arbusto & VS \\
\hline Mimosa pendula (Willd.) Poir. & arbusto & $\mathrm{SBC}$ \\
\hline Mimosa pudica $\mathrm{L}$. & hierba & $\mathrm{BE}, \mathrm{SBC}$ \\
\hline Pachyrhizus erosus (L.) Urb. & hierba & SBC \\
\hline Phaseolus vulgaris $\mathbf{L}$. & bejuco & $\mathrm{BE}$ \\
\hline Peltogyne mexicana Martínez & arbusto & $\mathrm{SBC}$ \\
\hline Pithecellobium dulce (Roxb.) Benth. & árbol & VG,SBC,VS \\
\hline Pterocarpus acapulcensis Rose & árbol & $\mathrm{SBC}, \mathrm{VS}$ \\
\hline $\begin{array}{l}\text { Senna alata (L.) Roxb. } \\
\text { Senna mollissima (Humb. \& Bonpl. ex Willd.) H.S. Irwin }\end{array}$ & arbusto & VG,SBC,VS \\
\hline \& Barneby & arbusto & SBC,VS \\
\hline Tephrosia Pers. & arbusto & SBC \\
\hline Tephrosia Pers. & arbusto & BEP \\
\hline Vigna sandwicensis A. Gray & hierba & BEP,VS \\
\hline
\end{tabular}


Apéndice 1. Continuación.

\section{Phylum/Clase/Familia/Nombre científico}

Zapoteca H.M. Hern.

Zornia thymifolia Kunth

\section{FAGACEAE}

Quercus castanea Née

Quercus peduncularis Née

Quercus candicans Née

\section{FLACOURTIACEAE}

Casearia obovata Schltdl.

Casearia tremula (Griseb.) Griseb. ex C. Wright

\section{GERANIACEAE}

Geranium seemannii Peyr.

\section{HIDROPHYLLACEAE}

Wigandia urens (Ruiz \& Pav.) Kunth

\section{KRAMERIACEAE}

Krameria cuspidata C. Presl

\section{LAMIACEAE}

Salvia elegans Vahl

Salvia hyptoides M. Martens \& Galeotti

Salvia mexicana $\mathrm{L}$.

Stachys coccinea Ortega

\section{LYTHRACEAE}

Cuphea P. Browne

\section{MALPIGHIACEAE}

Byrsonima crassifolia (L.) Kunth

Bunchosia palmeri $\mathrm{S}$. Watson

Malpighia mexicana A. Juss.

\section{MALVACEAE}

Anoda cristata (L.) Schltdl. (ENDEMICA DE MEXICO)

Herissantia crispa (L.) Brizicky

Sida acuta Burm. f.

\begin{tabular}{cc}
$\begin{array}{c}\text { Forma de } \\
\text { crecimiento }\end{array}$ & Vegetación \\
\hline $\begin{array}{c}\text { arbusto } \\
\text { hierba }\end{array}$ & SBC \\
\end{tabular}

árbol

BE,BP

arbusto

$\mathrm{BE}$

árbol

BE

arbusto

VG, SBC

arbusto

$\mathrm{SBC}$

hierba

BEP,BP,BE

arbusto

SBC, VS

arbusto

VS,SBC

hierba

SBC, VS

hierba

$\mathrm{BE}, \mathrm{BP}, \mathrm{BEP}, \mathrm{SBC}$

hierba

hierba

SBC,BE,BP

BEP

hierba

VS

arbusto

BC,BP,BEP

arbusto

SBC,BE,BEP

arbusto

SBC,BE

hierba

VG,BEP

hierba

SBC

hierba 
Apéndice 1. Continuación.

\section{Phylum/Clase/Familia/Nombre científico}

MELASTOMATACEAE

Clidemia hirta (L.) D. Don

Pterolepis pumila (Bonpl.) Cogn.

\section{MELIACEAE}

Swietenia humilis Zucc.

\section{MORACEAE}

Chlorophora tinctoria (L.) Gaudich. ex Benth.

Ficus insipida Willd.

Ficus padifolia Kunth

\section{MYRICACEAE}

Morella lindeniana (C. DC.) S. Knapp

\section{MYRSINACEAE}

Ardisia compressa Kunth

\section{MYRTACEAE}

Psidium sartorianum (O. Berg) Nied.

Psidium guajava L.

\section{NYCTAGINACEAE}

Okenia hypogaea Schltdl. \& Cham.

Salpianthus purpurascens (Cav. ex Lag.) Hook. \& Arn.

\section{ONAGRACEAE}

Lopezia racemosa Cav.

\section{OXALIDACEAE}

Oxalis corniculata L.

\section{POLYGONACEAE}

Coccoloba barbadensis Jacq.

Muehlenbeckia tamnifolia (Kunth) Meisn.

\section{PHYTOLACCACEAE}

Phytolacca rugosa A. Braun \& C.D. Bouché arbusto

\section{Forma de}

crecimiento

$\begin{array}{cc}\text { arbusto } & \text { VG,SBC } \\ \text { hierba } & \text { BEP }\end{array}$

árbol

SBC, VS

árbol

SBC

árbol

árbol

VG,SBC

VG

hierba

VG

arbusto

SBC,BE, VS

arbusto

SBC, VS

arbusto

SBC, VS,BE

hierba

SBC

arbusto

SBC

hierba

BE,SBC

hierba

SBC

hierba

SBC,BE,BEP

BEP,BP,BE

hierba

VS, SBC 
Apéndice 1. Continuación.

Phylum/Clase/Familia/Nombre científico

PRIMULACEAE

Anagallis arvensis L.

\section{RHIZOPHORACEAE}

Rhizophora mangle L.

\section{RUBIACEAE}

Coutarea latiflora Sessé \& Moc. ex DC.

Crusea calocephala DC.

Crusea coccinea DC.

Crusea wrightii A. Gray

Diodella teres (Walter) Small

Genipa americana L.

Randia cinerea (Fernald) Standl.

Randia echinocarpa Moc. \& Sessé ex DC.

\section{SALICACEAE}

Salix humboldtiana Willd.

\section{SAPINDACEAE}

Paullinia pinnata $\mathrm{L}$.

Thouinidium decandrum (Bonpl.) Radlk.

\section{SAPOTACEAE}

Mastichodendron capiri (A. DC.) Cronquist

\section{SOLANACEAE}

Jaltomata procumbens (Cav.) J.L. Gentry

Solanum marginatum L. f.

\section{SCROPHULARIACEAE}

Buchnera pusilla Kunth

Capraria saxifragifolia Schltdl. \& Cham.

Russelia tetraptera S.F. Blake

\section{STERCULIACEAE}

Guazuma ulmifolia Lam.

Helicteres guazumifolia Kunth

Melochia speciosa S. Watson

Melochia tomentella (C. Presl) Hemsl.

\section{Forma de crecimiento \\ Vegetación}

hierba

VS

arbusto

M

arbusto

SBC

hierba

BE,BP,BEP

hierba

BE,BP,BEP

hierba

BE, BP,BEP

hierba

$B E$

árbol

arbusto

SBC,BE,VS

$\mathrm{VS}, \mathrm{SBC}$

arbusto

SBC, VS

árbol

VG

árbol

VS

arbusto

SBC

árbol

VG,SBC,VS

hierba

BE,SBC

arbusto

VS

hierba

VS,P

hierba

BE,BP

hierba

$\mathrm{BE}, \mathrm{SBC}$

árbol

SBC,VS

arbusto

SBC, VS

arbusto

$\mathrm{VS}, \mathrm{SBC}$

hierba

$\mathrm{SBC}$ 
Apéndice 1. Continuación.

\section{Phylum/Clase/Familia/Nombre científico}

THEOPHRASTACEAE

Jacquinia macrocarpa Cav.

Jacquinia pungens A. Gray

\section{TILIACEAE}

Heliocarpus occidentalis Rose

Luehea candida (Moc. \& Sessé ex DC.) Mart.

Luehea speciosa Willd.

Muntigia calabura L.

Trichospermum grewiifolium (A. Rich.) Kosterm.

\section{ULMACEAE}

Trema micrantha (L.) Blume

\section{URTICACEAE}

Urera baccifera (L.) Gaudich. ex Wedd.

\section{TURNERACEAE}

Turnera ulmifolia $\mathrm{L}$.

Turnera violacea Brandegee

\section{VALERIANACEAE}

Valeriana urticifolia Kunth

\section{VERBENACEAE}

Avicennia germinans (L.) L.

Lantana camara $\mathrm{L}$.

Verbena longifolia M. Martens \& Galeotti

Vitex mollis Kunth

\section{VITACEAE}

Cissus salutaris Kunth

\section{CLASE LILIOPSIDA}

AMARYLLIDACEAE

Hymenocallis Salisb.

\section{COMMELINACEAE}

Commelina dianthifolia Delile

Cymbispatha commelinoides (Schult. \& Schult. f.) Pichón enredadera

$\begin{array}{cc}\text { arbusto } & \text { M } \\ \text { hierba } & \text { VS,SBC, } \\ \text { hierba } & \text { BE,SBC } \\ \text { arbusto } & \text { SBC,BE }\end{array}$

$\begin{array}{cc}\begin{array}{c}\text { Forma de } \\ \text { crecimiento }\end{array} & \text { Vegetació } \\ & \\ \text { arbusto } & \mathrm{SBC} \\ \text { arbusto } & \mathrm{VS}, \mathrm{SBC}\end{array}$

$\begin{array}{cc}\text { arbusto } & \mathrm{SBC} \\ \text { arbusto } & \mathrm{VS}, \mathrm{SBC} \\ \text { arbusto } & \mathrm{SBC}, \mathrm{VS} \\ \text { árbol } & \mathrm{SBC}, \mathrm{VS} \\ \text { árbol } & \mathrm{VS}, \mathrm{SBC}\end{array}$

árbol

$\mathrm{SBC}, \mathrm{VS}$

arbusto

SBC, VS

$\begin{array}{cc}\text { hierba } & \mathrm{SBC} \\ \text { hierba } & \mathrm{BE}\end{array}$

hierba

BP,BEP

hierba

VG

hierba

BEP,BP,BE

hierba

$\mathrm{BE}$ 
Apéndice 1. Conclusión.

\begin{tabular}{lcc}
\hline Phylum/Clase/Familia/Nombre científico & $\begin{array}{c}\text { Forma de } \\
\text { crecimiento }\end{array}$ & Vegetación \\
\hline CYPERACEAE &
\end{tabular}

Cyperus laxus Lam.

hierba

BE,BEP

Cyperus rotundus $\mathbf{L}$.

hierba

SBC, VS

Cyperus tenerrimus J. Presl \& C. Presl

hierba

BE,BEP

Schoenoplectus sp.

hierba

$\mathrm{T}$

\section{IRIDACEAE}

Cipura paludosa Aubl.

hierba

BE

\section{LILIACEAE}

Bessera elegans Schult. f.

hierba

BE,BP

Echeandia flexuosa Greenm.

hierba

$\mathrm{BP}, \mathrm{BEP}, \mathrm{BE}$

\section{MARANTACEAE}

Maranta arundinacea L.

hierba

VS, SBC

\section{POACEAE}

Arundinella ravii Shaju \& Mohanan

hierba

BE

Andropogon gayanus Kunth

hierba

$$
\mathrm{P}
$$

Andropogon L.

hierba

Cynodon dactylon (L.) Pers.

hierba

VS,P

Digitaria hackelii (Pilg.) Stapf

hierba

$P, V S$

Hyparrhenia rufa (Nees) Stapf

hierba

BE,SBC

Muhlenbergia tenuifolia (Kunth) Trin.

hierba

$\mathrm{P}, \mathrm{VS}$

Oplismenus P. Beauv.

hierba

$\mathrm{P}, \mathrm{VS}$

Panicum maximum Jacq.

hierba

VS

Panicum trichoides Sw.

hierba

$\mathrm{P}, \mathrm{SBC}$

Paspalum fasciculatum Willd. ex Flüggé

hierba

P,SBC,BEP

Paspalum sparsum Chase

hierba

BE,VS

Pinnesetum sp.

hierba

$\mathrm{P}, \mathrm{VS}$

Rhynchelytrum repens (Willd.) C.E. Hubb.

hierba

VS

Setaria parviflora (Poir.) Kerguélen

hierba

$\mathrm{P}, \mathrm{BE}$

$\mathrm{P}$

\section{PHYLUM CONIFEROPHYTA}

\section{CLASE PINOPSIDA}

\section{PINACEAE}

Pinus oocarpa Schiede ex Schltdl.

árbol

BP,BEP

El tipo de vegetación se asigna de la siguiente manera: $\mathrm{SBC}=$ selva baja caducifolia, $\mathrm{BE}=$ bosque de encino, $\mathrm{VS}=$ vegetación secundaria, $\mathrm{VG}=$ vegetación galería, $\mathrm{BEP}=$ bosque de encino-pino, $\mathrm{P}=$ pastizal, $\mathrm{BP}=$ bosque de pino, $\mathrm{M}=$ manglar, $\mathrm{BC}=$ bosque de Curatella americana, $\mathrm{SMS}=$ selva mediana subcaducifolia, $\mathrm{T}=$ tular. 